\title{
Analisis Pengaruh Kredibilitas Endorser DAI Dalam Iklan Terhadap Minat Beli Pada Produk Telkomsel
}

\author{
Kiki Wulandari \\ ${ }^{1}$ Universitas Islam Indonesia, Yogyakarta, DIY Yogyakarta, 55283, Indonesia
}

\begin{abstract}
ABSTRAK : Tujuan dari penelitian ini adalah untuk mengetahui apakah daya tarik, kepercayaan, keahlian memiliki pengaruh positif terhadap sikap terhadap iklan dan apakah sikap terhadap iklan memiliki pengaruh positif terhadap minat beli. Populasi dari penelitian ini adalah masyarakat di Daerah Istimewa Yogyakarta yang menggunakan layanan provider Telkomsel. Data dianalisis dengan bantuan AMOS. Hasil analisa menunjukkan bahwa daya tarik berpengaruh signifikan terhadap sikap terhadap iklan, kepercayaan berpengaruh signifikan terhadap sikap terhadap iklan, keahlian berpengaruh signifikan terhadap sikap terhadap iklan, sikap terhadap iklan berpengaruh signifikan terhadap minat beli.
\end{abstract}

Kata kunci : daya tarik, kepercayaan, keahlian, sikap terhadap iklan, minat beli

\begin{abstract}
This research aimed to examine the effect of the attractiveness, trustworthiness, expertise toward attitude toward advertisement and attitude toward advertisement toward purchase intention. The research respondent were the people in DIY who use Telkomsel provider. Data were analized with AMOS. The result of analyze showed that the attractiveness had a significant influence to attitude toward advertisement, trustworthiness had a significant influence to attitude toward advertisement, expertise had a significant influence to attitude toward advertisement, attitude toward advertisement had a significant influence to purchase intention.
\end{abstract}

Keywords : attractiveness, trustworthiness, expertise, attitude toward advertisement, purchase intention

Email Address : kikiwulandari92@gmail.com

\section{PENDAhULUAN}

Pada era globalisasi saat ini, persaingan dalam dunia bisnis semakin dinamis, kompleks dan serba tidak pasti. Dengan keadaan ekonomi yang kurang menentu dan pasar yang berubah-ubah mengakibatkan iklim persaingan semakin ketat dalam dunia bisnis. Hal ini yang menyebabkan perusahaan harus memiliki keunggulan kompetitif agar mampu bersaing dengan banyak industri untuk mempertahankan konsumen bahkan meluaskan pangsa pasarnya.
Nurmalita(2011) menjelaskan bahwa setiap perusahaan berusaha menarik perhatian (calon) konsumen melalui pemberian informasi tentang produk. Bagi perusahaaan besar, iklan adalah salah satu pilihan strategi yang paling menarik karena sumber iklan selain sebagai informasi yang efektif dapat menjadi media hiburan. Menurut Adiputra (2013) iklan didefinisikan sebagai pesan yang menawarkan suatu produk yang ditujukan kepada masyarakat lewat suatu media. Pada dasarnya, tujuan utama dari sebuah iklan 
adalah untuk membuat produk atau merek dikenal, dan untuk membantu terciptanya kesadaran instan sesuai yang di jelaskan oleh Joshi (2003). Salah satu upaya membuat iklan agar menarik adalah dengan menampilkan daya pikat tertentu dalam iklan. Shimp (2003) menyebutkan bahwa ada beberapa upaya yang bisa dilakukan untuk membuat iklan menarik, yaitu: menjadikan selebriti sebagai endorser (pendukung), yang menggunakan humor, pemakaian rasa bersalah, dan memakai unsur seksual. Sallam dan Wahid (2012) menjelaskan bahwa penggunaan selebriti sebagai juru bicara untuk perusahaan menjadi metode periklanan yang populer, alasan dibalik popularitas iklan seleberiti adalah kepercayaan pengiklan bahwa pesan yang disampaikan oleh tokoh-tokoh mendapatkan perhatian tingkat tinggi dan mudah untuk diingat oleh beberapa konsumen.

Iklan yang cukup sering muncul di televisi adalah iklan operator seluler dan salah satunya adalah iklan produk Telkomsel. Iklan produk Telkomsel cukup mendapat tempat dihati konsumen. Iklan pada produk Telkomsel digunakan sebagai studi kasus dengan alasan utama yaitu penggunaan para selebriti dalam iklannya sebagai endorser.

Dari uraian diatas, maka penulis tertarik untuk meneliti lebih lanjut guna mengungkapkan sejauh mana pengaruh kredibilitas endorser yang dimiliki ustad Maulana terhadap minat beli konsumen. Jika yang ditampilkan oleh pengiklan telah benar-benar memenuhi syarat, maka tentunya akan mendapatkan respon positif dan jika belum memenuhi maka akan kurang mendapat respon positif atau bahkan akan mendapat respon negatif. Dengan melihat permasalahan di atas untuk penelitian ini maka diambilah judul "Analisis Pengaruh Kredibilitas Endorser Da'i dalam Iklan Terhadap Minat Beli Konsumen pada Produk Telkomsel di DIY"

\section{KAJIAN PUSTAKA Attractiveness}

Menurut O'Mahony dan Meenaghan (1998: 15-24) daya tarik adalah kemampuan selebritis dalam menyampaikan iklannya kepada pasar sasaran, semakin identik dan popular selebritis yang digunakan maka semakin cepat pula konsumen dalam mengenal iklan disampaikan.

Ohanian (1991) menjelaskan bahwa pembawa pesan iklan (endorser) dipersepsikan sebagai seseorang yang secara fisik menarik atau menyenangkan sering dapat menyebabkan sikap yang positif dan respons perilaku dari konsumen. Menurut Shimp (2003) attractiveness bukan hanya berarti daya tarik fisik, meskipun attractiveness bisa menjadi atribut yang sangat penting tetapi meliputi sejumlah karakteristik yang dapat dilihat khalayak dalam diri pendukung, kecerdasan, sifat-sifat kepribadian, gaya hidup, dan keatletisan postur tubuh.

Solomon et al. (1992) mengatakan bahwa juru bicara yang attractive lebih efektif dibandingkan dengan yang tidak attractive dalam iklan dan promosi.

Oleh karena itu hipotesis yang diajukan dalam penelitian ini adalah :

H1:Daya tarik berpengaruh secara positif terhadap sikap terhadap iklan

\section{Trustworthiness}

Menurut O'Mahony dan Meenaghan (1998: 15-24) kepercayaan adalah perasaan atau apresiasi yang diberikan oleh konsumen terhadap iklan sehingga perilaku obyek atau subyek dapat mempengaruhi konsumen terhadap iklan yang disampaikan.

Menurut Shimp keterpercayaan tentang selebriti yang dianggap memiliki wawasan tentang isu tertentu dan dapat dipercaya, seperti 
kehandalan merek, akan menjadi orang yang paling mampu meyakinkan orang lain untuk mengambil suatu tindakan keputusan pembelian. Selebriti yang digunakan sebagai model iklan sebaiknya mempunyai keterpercayaan sehingga konsumen sebagai penerima pesan iklan meyakini bahwa mereka mempunyai pengetahuan dan pengalaman (O’Mahony dan Meenaghan dalam Noviandra, 2006).

Ohanian (1990) mengemukakan bahwa sebuah pesan iklan dapat merubah sikap audiencnya jika mereka menganggap bahwa pembawa pesan dapat dipercaya.

Oleh karena itu hipotesis yang diajukan adalah :

H2: Kepercayaan berpengaruh secara positif terhadap sikap terhadap iklan

\section{Expertise}

Menurut O'Mahony dan Meenaghan (1998: 15-24) keahlian adalah kemampuan spesifik yang dimiliki oleh obyek maupun subyek iklan berdasarkan pengalaman maupun kemampuan pasar sasaran yang merupakan tujuan produsen.

Johnston (2001) menjelaskan bahwa konsumen mempersepsikan produk atau merek yang diiklankan oleh selebriti yang mempunyai citra expertise dan trustworthiness sebagai produk atau merek yang kredibel.

Hal ini memberikan konsumen sebuah referensi dalam membandingkan attribute produk dan memudahkan mereka dalam memilih produk yang akan dibelinya (Ohanian, 1991). Sedangkan menurut Erdogan dalam Ahmed et al. (2012) keuntungan menggunakan endorser yang ahli adalah meningkatkan brand recall dan positif mempengaruhi niat beli konsumen.

Dalam hasil temuan Goldsmith et al. (2000) mengatakan bahwa kredibilitas bintang iklan berpengaruh secara positif terhadap sikap terhadap iklan.
Oleh karena itu hipotesis yang diajukan adalah :

H3:Keahlian berpengaruh secara positif terhadap sikap terhadap iklan.

\section{Sikap terhadap Iklan}

Biehal et al. (1992) mendefinisikan sikap terhadap iklan (attitude toward the Ad) sebagai suatu kecenderungan untuk merespon dengan cara yang baik atau tidak baik suatu stimuli iklan tertentu dalam suatu situasi eksposur tertentu. Dari hasil temuan Goldsmith et al. (2000) melalui suatu model eksperimen yang menunjukkan bahwa sikap terhadap iklan secara langsung berpengaruh pada niat beli untuk produk yang familiar dan yang unfamiliar. Penelitia ini diperkuat dengan hasil penelitian Ishak (2008) mengatakan banyak studi empiris yang menunjukkan adanya pengaruh langsung dari sikap terhadap iklan terhadap niat beli konsumen.

Oleh karena itu hipotesis yang diajukan adalah :

H4:Sikap terhadap iklan berpengaruh secara positif terhadap minat beli.

\section{Minat Beli}

Minat beli merupakan bagian dari komponen perilaku konsumen dalam sikap mengkonsumsi, kecendrungan responden untuk bertindak sebelum keputusan membeli benar-benar dilaksanakan. Minat (intention) merupakan variabel antara yang menyebabkan terjadinya perilaku dari suatu sikap atau variabel lainnya.

Markin Jr dalam Effendy (1999) menyatakan minat membeli adalah suatu aktivitas psikis yang timbul karena adanya pikiran dan perasaan senang terhadap suatu obyek yang diinginkan berupa barang atau jasa. Minat itu sendiri adalah kelanjutan dari perhatian yang merupakan titik tolak bagi timbulnya hasrat atau keinginan (desire) 
untuk melakukan sesuatu kegiatan yang diharapkan komunikator, jadi minat dalam membeli dapat dikatakan timbulnya keinginan seseorang untuk mencoba membeli produk yang diiklankan tersebut.

\section{METODE PENELITIAN}

\section{Model Penelitian}

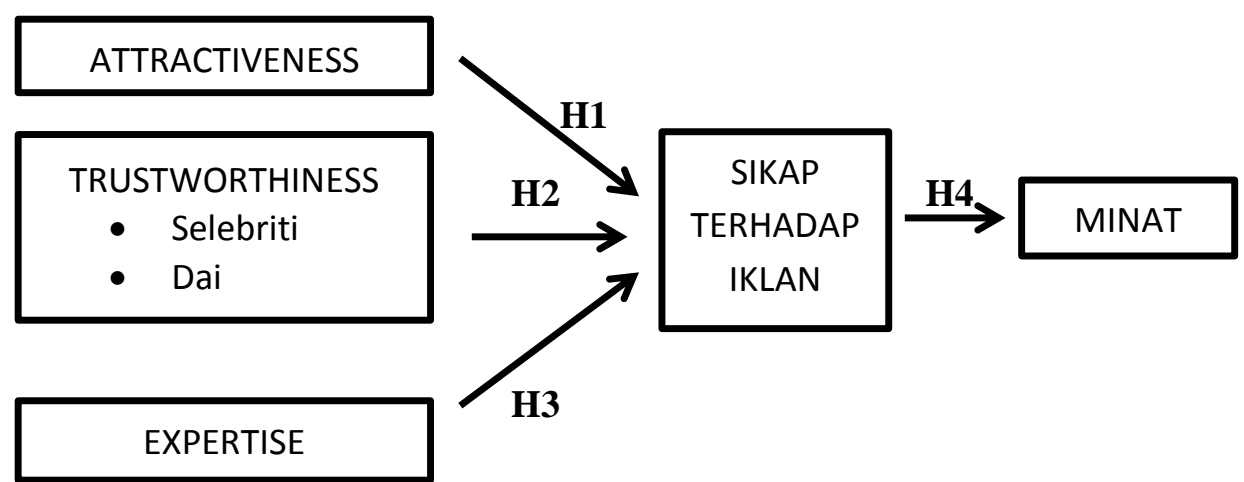

\section{Jenis dan Teknik Pengumpulan Data}

Jenis data yang digunakan dalam penelitian ini adalah data primer. Data primer yaitu data yang diperoleh langsung dari objek penelitian dengan menggunakan alat pengukuran atau alat pengambilan data langsung pada subyek sebagai sumber informasi yang dicari. Dalam penelitian ini data diperoleh dengan menggunakan kuesioner yang dibagikan pada 300 responden.

\section{Teknik Analisis}

Teknis analisis yang digunakan pada penelitian ini adalah dengan menggunakan analisis structural equation modeling (SEM), mengingat model konseptual penelitian ini mempunyai dua dependen dan tiga independent variabel. Model seperti ini tidak bisa dianalisa dengan Analisa Regresi berganda. SEM adalah teknik analisis yang memungkinkan menganalisa pengaruh beberapa variabel terhadap variabel yang lain secara simultan (Ghozali, 2008).

Tabel : Hasil Perhitungan Validitas dan Reliabilitas Data

\begin{tabular}{|l|c|c|c|}
\hline \multicolumn{1}{|c|}{ Indikator } & Validitas & Reliabilitas & Rata-rata \\
\hline \multicolumn{1}{|c|}{ Attractiveness } & $\mathbf{0 , 6 4 1}$ & $\mathbf{2 , 9 7}$ \\
Penampilan Bintang iklan tersebut & 0,001 & & 2,79 \\
$\begin{array}{l}\text { Menarik } \\
\text { Penampilan Bintang iklan tersebut }\end{array}$ & 0,000 & & 3,00 \\
$\begin{array}{l}\text { Berkharisma } \\
\text { Penampilan Bintang iklan tersebut }\end{array}$ & 0,000 & & 3,07 \\
$\begin{array}{l}\text { Elegan } \\
\text { Penampilan Bintang iklan tersebut }\end{array}$ & 0,000 & & 3,12 \\
$\begin{array}{l}\text { Berkelas } \\
\text { Bintang iklan tersebut tampan }\end{array}$ & 0,000 & & 2,87 \\
\hline $\begin{array}{l}\text { Trustworthiness } \\
\text { Bintang iklan tersebut seorang yang } \\
\text { dapat dihandalkan }\end{array}$ & 0,000 & $\mathbf{0 , 8 8 9}$ & $\mathbf{3 , 0 0}$ \\
\end{tabular}




\begin{tabular}{|c|c|c|c|}
\hline $\begin{array}{l}\text { Bintang iklan tersebut jujur dalam } \\
\text { menyampaikan pesan iklan }\end{array}$ & 0,000 & & 2,96 \\
\hline $\begin{array}{l}\text { Bintang iklan tersebut konsisten } \\
\text { dalam menyampaikan pesan iklan }\end{array}$ & 0,000 & & 3,00 \\
\hline $\begin{array}{l}\text { Bintang iklan tersebut tulus dalam } \\
\text { menyampaikan pesan iklan }\end{array}$ & 0,000 & & 3,06 \\
\hline $\begin{array}{l}\text { Bintang iklan tersebut dapat } \\
\text { dipercaya }\end{array}$ & 0,000 & & 3,10 \\
\hline $\begin{array}{l}\text { Endorser dai (orang yang mendalami } \\
\text { agama) seharusnya lebih JUJUR } \\
\text { dibanding endorser selebriti lainnva }\end{array}$ & 0,000 & & 2,98 \\
\hline $\begin{array}{l}\text { Endorser dai (orang yang mendalami } \\
\text { agama) seharusnya lebih DAPAT } \\
\text { DIPERCAYA dibanding endorser }\end{array}$ & 0,000 & & 2,98 \\
\hline $\begin{array}{l}\text { selebriti lainnya } \\
\text { s.ting }\end{array}$ & & & \\
\hline $\begin{array}{l}\text { Endorser dai (orang yang mendalami } \\
\text { agama) seharusnya lebih DAPAT } \\
\text { MENJADI PANUTAN dibanding } \\
\text { endorser selebriti lainnya }\end{array}$ & 0,000 & & 3,00 \\
\hline Expertise & & $\mathbf{0 , 8 2 3}$ & 2,85 \\
\hline $\begin{array}{l}\text { Bintang iklan tersebut seorang yang } \\
\text { ahli }\end{array}$ & 0,000 & & 2,80 \\
\hline $\begin{array}{l}\text { Bintang iklan tersebut seorang yang } \\
\text { berpengalaman }\end{array}$ & 0,000 & & 3,02 \\
\hline $\begin{array}{l}\text { Bintang iklan tersebut seorang yang } \\
\text { berpengetahuan luas }\end{array}$ & 0,005 & & 2,72 \\
\hline $\begin{array}{l}\text { Bintang iklan tersebut seorang yang } \\
\text { berkualitas }\end{array}$ & 0,000 & & 2,79 \\
\hline $\begin{array}{l}\text { Bintang iklan tersebut seorang yang } \\
\text { terampil }\end{array}$ & 0,000 & & 2,94 \\
\hline $\begin{array}{l}\text { Bintang iklan tersebut seorang yang } \\
\text { informative }\end{array}$ & 0,000 & & 2,97 \\
\hline $\begin{array}{l}\text { Ustad Maulana familiar dengan } \\
\text { produk yg diiklankannya }\end{array}$ & 0,000 & & 2,46 \\
\hline $\begin{array}{l}\text { Ustad Maulana cocok dalam } \\
\text { mengiklankan produk tsb }\end{array}$ & 0,000 & & 3,07 \\
\hline Sikap terhadap Iklan & & 0,741 & 2,93 \\
\hline Iklan tersebut dapat dipercaya & 0,014 & & 2,96 \\
\hline Iklan tersebut nampak meyakinkan & 0,000 & & 2,80 \\
\hline Iklan tersebut nampak jujur & 0,030 & & 2,97 \\
\hline $\begin{array}{l}\text { Iklan tersebut kreatif, membuat saya } \\
\text { tertarik }\end{array}$ & 0,000 & & 2,76 \\
\hline Iklan tersebut tidak meragukan & 0,000 & & 2,88 \\
\hline Iklan tersebut bermanfaat & 0,047 & & 2,94 \\
\hline Iklan tersebut menarik & 0,000 & & 2,94 \\
\hline Iklan tersebut bagus (baik) & 0,004 & & 2,99 \\
\hline Iklan tersebut menyenangkan & 0,047 & & 2,97 \\
\hline Iklan tersebut dapat dinikmati & 0,000 & & 2,89 \\
\hline Iklan tersebut tidak membosankan & 0,048 & & 3,00 \\
\hline Iklan tersebut berkesan modern & 0,042 & & 2,90 \\
\hline
\end{tabular}




\begin{tabular}{|c|c|c|c|}
\hline $\begin{array}{l}\text { Iklan tersebut berkesan seksi } \\
\text { Pesan didalam Iklan kuat } \\
\text { Pesan Iklan efektif }\end{array}$ & $\begin{array}{l}0,000 \\
0,049 \\
0,000\end{array}$ & & $\begin{array}{l}2,97 \\
3,02 \\
2,94 \\
\end{array}$ \\
\hline Minat Beli & & 0,609 & 2,92 \\
\hline $\begin{array}{l}\text { Saya akan mencari tau lebih lanjut } \\
\text { mengenai produk ini }\end{array}$ & 0,000 & & 2,97 \\
\hline $\begin{array}{l}\text { Saya akan mempertimbangkan untuk } \\
\text { membeli produk ini }\end{array}$ & 0,000 & & 2,91 \\
\hline $\begin{array}{l}\text { Saya sungguh-sungguh ingin } \\
\text { membeli produk ini }\end{array}$ & 0,000 & & 2,89 \\
\hline
\end{tabular}

\section{HASIL PENELITIAN DAN PEMBAHASAN}

Dari tabel diatas dapat dilihat hasil Uji Validitas Item-item Variabel Independen yang diketahui bahwa nilai sig. $<0,05$, sehingga seluruh item-item pertanyaan pada variabel attractiveness, trustworthiness, dan expertise adalah valid. Dan Hasil Uji Validitas untuk Item-item Variabel Dependen diketahui nilai sig. $<0,05$, sehingga seluruh itemitem pertanyaan pada variabel sikap terhadap iklan dan minat beli adalah valid. Untuk Koefisien diketahui bahwa Cronbach's Alpha > 0,60 sehingga seluruh item-item pertanyaan pada variabel attractiveness, trustworthiness, dan expertise, sikap terhadap iklan, dan minat beli adalah reliabel.

Dilihat dari tabel diatas sebagian besar responden menilai attractiveness, Setuju (Mean 2,97). Dengan rata-rata tertinggi terdapat di indikator pertanyaan penampilan ustad Maulana berkelas (Mean 3,12) dan rata-rata terendah terdapat di indikator pertanyaan penampilan ustad Maulana menarik (Mean 2,79). Untuk variabel trustworthines sebagian besar responden, Setuju (Mean 3,00). Dengan rata-rata tertinggi terdapat di indikator pertanyaan ustad Maulana dapat dipercaya (Mean 3,10) dan rata-rata terendah terdapat di indikator pertanyaan ustad Maulana orang yang dapat dihandalkan (Mean 2,91). sebagian besar responden menilai expertise, Setuju (Mean 2,85). Dengan rata-rata tertinggi terdapat di indikator pertanyaan ustad Maulana cocok dalam mengiklankan produk tersebut (Mean $3,07)$ dan rata-rata terendah terdapat di indikator pertanyaan ustad Maulana familiar dengan produk yang diiklankannya (Mean 2,46). Untuk Sikap terhadap iklan responden menilai, Setuju (Mean 2,93). Dengan rata-rata tertinggi terdapat di indikator pertanyaan pesan didalam iklan Telkomsel kuat (Mean 3,02) dan rata-rata terendah terdapat di indikator pertanyaan iklan Telkomsel kreatif membuat saya tertarik (Mean 2,97). Dan sebagian besar responden menilai minat beli, Setuju (Mean 2,92). Dengan rata-rata tertinggi terdapat di indikator pertanyaan saya akan mencari tau lebih lanjut mengenai produk Telkomsel (Mean 2,97) dan rata-rata terendah terdapat di indikator pertanyaan saya sungguh-sungguh ingin membeli produk Telkmosel (Mean 2,89).

\section{Goodness of Fit}

Hasil uji normalitas bahwa nilai RMSEA < nilai kritisnya $=0,080$, GFI $>0,90$, dan TLI dan CFI $\geq 0,90$. Hal ini berarti model persamaan structural dalam penelitian ini adalah fit (memiliki kesesuaian)

\section{Hasil Structural Equation Model}




\begin{tabular}{|l|c|c|c|c|}
\hline \multicolumn{1}{|c|}{ Variabel } & $\begin{array}{c}\text { Koefisien } \\
\text { Regresi }\end{array}$ & t-hitung & Prob. & Keterangan \\
\hline Attractivness $\left(\mathrm{X}_{1}\right)-\mathrm{Y}_{1}$ & 0,198 & 6,526 & 0,000 & Diterima \\
\hline Trustworthiness $\left(\mathrm{X}_{2}\right)-\mathrm{Y}_{1}$ & 0,102 & 3,872 & 0,000 & Diterima \\
\hline Expertise $\left(\mathrm{X}_{3}\right)-\mathrm{Y}_{1}$ & 0,161 & 6,802 & 0,000 & Diterima \\
\hline Sikap terhadap iklan $\left(\mathrm{Y}_{1}\right)-\mathrm{Y}_{2}$ & 0,953 & 7,482 & 0,000 & Diterima \\
\hline $\mathrm{N}$ & & & \\
\hline Variabel Dependen $\left(\mathrm{Y}_{1}, \mathrm{Y}_{2}\right)$ & & & \\
\hline
\end{tabular}

\section{Hipotesis 1}

Dengan taraf nyata (probabilitas) $=5 \%$ $=0,05$ dan dari hasil Regresi SEM diperoleh probabilitas $t_{\text {-hitung }}=0,000$. Berdasarkan hasil olah data diperoleh nilai probabilitas $\mathrm{t}_{\text {-hitung }}(0,000)<$ Level of Significant $(0,05)$, maka disimpulkan bahwa variabel attractiveness $\left(\mathrm{X}_{1}\right)$ berpengaruh signifikan terhadap sikap terhadap iklan $\left(\mathrm{Y}_{1}\right)$. Berdasarkan hasil pengujian hipotesis seperti yang telah dipaparkan, maka H1 diterima. Attractiveness (daya tarik) memiliki pengaruh positif terhadap sikap terhadap iklan.

\section{Hipotesis 2}

Dengan taraf nyata (probabilitas) $=5 \%$ $=0,05$ dan dari hasil Regresi SEM diperoleh probabilitas $t_{\text {-hitung }}=0,000$. Berdasarkan hasil olah data diperoleh nilai probabilitas $\mathrm{t}_{\text {-hitung }}(0,000)<$ Level of Significant $(0,05)$, maka disimpulkan bahwa variabel trustworthiness $\left(\mathrm{X}_{2}\right)$ berpengaruh signifikan terhadap sikap terhadap iklan $\left(\mathrm{Y}_{1}\right)$. Berdasarkan hasil pengujian hipotesis seperti yang telah dipaparkan, maka H2 diterima. Trustworthiness (kepercayaan) memiliki pengaruh positif terhadap sikap tehadap iklan.

\section{Hipotesis 3}

Dengan taraf nyata (probabilitas) $=5 \%$ $=0,05$ dan dari hasil Regresi SEM diperoleh probabilitas $t_{\text {-hitung }}=0,000$. Berdasarkan hasil olah data diperoleh nilai probabilitas $\mathrm{t}_{\text {-hitung }}(0,000)<$ Level of Significant $(0,05)$, maka disimpulkan bahwa variabel expertise $\left(\mathrm{X}_{3}\right)$ berpengaruh signifikan terhadap sikap terhadap iklan $\left(\mathrm{Y}_{1}\right)$. Berdasarkan hasil pengujian hipotesis seperti yang telah dipaparkan, maka H3 diterima. Expertise (keahlian) memiliki pengaruh positif terhadap sikap terhadap iklan.

\section{Hipotesis 4}

Dengan taraf nyata (probabilitas) $=5 \%$ $=0,05$ dan dari hasil Regresi SEM diperoleh probabilitas $t_{\text {-hitung }}=0,000$. Berdasarkan hasil olah data diperoleh nilai probabilitas $\mathrm{t}_{\text {-hitung }}(0,000)<$ Level of Significant $(0,05)$, maka disimpulkan bahwa variabel sikap terhadap iklan $\left(\mathrm{Y}_{1}\right)$ berpengaruh signifikan terhadap minat beli $\left(\mathrm{Y}_{2}\right)$. Berdasarkan hasil pengujian hipotesis seperti yang telah dipaparkan, maka $\mathrm{H} 4$ diterima. Attitude toward Ad (sikap terhadap iklan) memiliki pengaruh positif terhadap minat beli.

\section{PENUTUP Kesimpulan}

Penelitian ini bertujuan untuk mengetahui mengenai analisis pengaruh kredibilitas endorser (dai: ustad Maulana) dalam iklan terhadap minat beli konsumen di DIY. Ada 4 hipotesis yang diajukan dalam penelitian. Dari 
hasil pengolahan data, peneliti dapat menyimpulkan bahwa:

Hasil analisis Structural

Equation Model (SEM) mengenai hasil pengujian hipotesis menunjukkan bahwa variabel attractiveness berpengaruh signifikan terhadap sikap terhadap iklan. Ini dapat dilihat pada nilai $\mathrm{t}$-hitung $=$ 6,526 dibandingkan dengan t-tabel = 1,96 dan juga koefisien regresi sebesar 0,198 . Hal ini dapat diartikan, jika attractiveness meningkat, maka sikap terhadap iklan akan mengalami peningkatan.

Hasil analisis Structural Equation Model (SEM) mengenai hasil pengujian hipotesis menunjukkan bahwa variabel trustworthiness berpengaruh signifikan terhadap sikap terhadap iklan. Ini dapat dilihat pada nilai t-hitung $=3,872$ dibandingkan dengan t-tabel $=1,96$ dan juga koefisien regresi sebesar 0,102 . Hal ini dapat diartikan, jika trustworthiness meningkat, maka sikap terhadap iklan akan mengalami peningkatan.

Hasil analisis Structural Equation Model (SEM) mengenai hasil pengujian hipotesis menunjukkan bahwa variabel expertise berpengaruh signifikan terhadap sikap terhadap iklan. Ini dapat dilihat pada nilai t-hitung $=6,802$ dibandingkan dengan t-tabel $=1,96$ dan juga koefisien regresi sebesar 0,161 . Hal ini dapat diartikan, jika expertise meningkat, maka sikap terhadap iklan akan mengalami peningkatan.

Hasil analisis Structural Equation Model (SEM) mengenai hasil pengujian hipotesis menunjukkan bahwa variabel sikap terhadap iklan mempunyai pengaruh signifikan terhadap terhadap Minat beli. Ini dapat dilihat pada nilai thitung $=7,482$ dibandingkan dengan $\mathrm{t}$ tabel $=1,96$ dan juga koefisien regresi

\section{DAFTAR PUSTAKA}

Adiputra,Y.P. 2013. Pengaruh Persepsi Konsumen pada Iklan Berseri terhadap Sikap dan Niat Beli sebesar 0,953. Hal ini dapat diartikan, jika sikap terhadap iklan meningkat, maka terhadap minat beli akan mengalami peningkatan.

\section{Keterbatasan Penelitian dan Saran}

Pada penelitian ini wilayah penelitian hanya pada Kota Yogyakarta sehingga penelitian selanjutnya diharapkan untuk memperluas wilayah penelitian untuk memperoleh hasil penelitian yang lebih reliable dan relevan.

Penelitian ini hanya menganalis iklan yang menggunakan endorser (dai) dengan asumsi bahwa iklan tersebut lebih efektif dalam menciptakan minat beli daripada yang menggunakan bintang iklan yang berasal dari non selebriti. Diharapkan untuk penelitian di masa yang akan datang dapat membandingkan antara iklan yang menggunakan selebriti dengan iklan yang menggunakan endorser non selebriti dalam mengevaluasi sikap terhadap iklan.

Berkaitan dengan dominan signifikannya pengaruh attractiveness terhadap minat beli pada produk Telkomsel, maka dapat diberikan saran untuk lebih meningkatkan attractivness dengan cara pihak Telkomsel melalui media televisi selalu membuat dan menjaga penampilan Ustad Maulana menarik, selalu membuat dan menjaga penampilan Ustad Maulana berkharisma, selalu membuat, dan menjaga penampilan Ustad Maulana elegan dan berkelas. Dengan demikian, maka sikap terhadap minat beli pada produk Telkomsel akan meningkat lebih signifikan.

Konsumen (Iklan Kartu As Telkomsel, Versi Kimmy). Skrpsi, Universitas Islam Indonesia 
Biehal, Gabriel, Stephen, Debra, and Curlo, Eleonora. 1992. Attitude Toward the Ad Brand Choice, Journal of Advertising, 21 (3), 19-36

Efendi, S. 1999. Pengaruh Penggunaan Group Band Dewa Dalam Iklan Oli Top 1 Di Media Televisi Terhadap Minat Membeli oleh Konsumen, Jurnal Siasat Bisnis. No.4 Vol.1, Maret

Erdogan, B. Z. 1999. Celebrity endorsement: A literature review. Journal of Marketing Management, 15(4): 291-314

Ghozali, I. 2008. Model Persamaan Struktural Konsep dan Aplikasi dengan Program Amos 16.0, Badan Penerbit UNDIP, Semarang

Goldsmith, R.E, Lafferty,B.A., and Newell, S.J. 2000. The Impact of Corporate Credibility on Consumer Reaction and Brands, Journal of Advertising, 44-54

Ishak, A. 2008. Pengaruh Pengunaan Selebriti dalam Iklan terhadap Minat Beli Konsumen, Jurnal Siasat Bisnis. Vol. 12 No. 2, Agustus $2008 \mathrm{Hal}$ 71-88

Johnston, R. 2001. Credibility and Celebrity Endorsements, http://www.ciadvertising.org/studen t_account/fall_01/adv382j/russj/cel ebrity.html

Joshi,S. 2003. Face Value: A Celebrity is Used to Impart Credibility and Aspirational values to a Brand but the Celebrity Needs to Match the Product, Business line. Chennai, April 24, 2003, 1
Noviandra, M. 2006. Analisis Pengaruh Model Iklan Terhadap Perilaku Pembelian Remaja, Kasus Pada Bintang Akademi Fantasi Indosiar

Nurmalita,A.M. 2011.Pengaruh Pemakaian Endorser Dalam IklanTelevisiMela lui Kepribadian Merek dan Impli kasinya Terhadap Citra Merek Pembalut Wanita Charm. Skri psi, Universitas Diponegoro

O’Mahony, S. dan Meenaghan, T. 1998. The Impact of Celebrity Endoserment on Consumers, Irish Marketing Review, 10,2, pp. 15-24

Ohanian, R. 1990. Construction and validation of a scale to measure celebrity, Journal of Advertising, Vol. 19, pp. 39-53

Ohanian, R. 1991. The impact of celebrity spokespersons' perceived image on consumers' intention to purchase, Journal of Advertising Research, 46-53

Sallam, M.M.A. and Wahid,N.A. 2012. Endorser Credibility Effects on Yemeni Male Consumer's Attitudes towards Advertising, Brand Attitude and Purchase Intention: The Mediating Role of Attitude toward Brand, International Business Research, Vol. 5, No. 4; April 2012

Shimp,T.A.2003.Periklanan Promosi, Jakarta : Erlangga.

Solomon, M.R., Ashmore, R.D. and Longo, L.C. 1992. The Beauty Match-Up Hypothesis: Congruence between Types of Beauty and Product Images in Advertising, Journal of Advertising, (21) (December), (4), pp. 23-34 